\title{
Does the habitual mastication side impact jaw muscle activity?
}

\author{
Karina Helga Leal Turcio ${ }^{\mathrm{a}, *}$, Paulo Renato Junqueira Zuim ${ }^{\mathrm{a}}$, Aimée Maria Guiottia \\ Daniela Micheline dos Santos ${ }^{\mathrm{a}}$, Marcelo Coelho Goiato ${ }^{\mathrm{a}}$, Daniela Atili Brandini ${ }^{\mathrm{b}}$ \\ a Department of Dental Materials and Prosthodontics, Araçatuba Dental School, UNESP-Univ Estadual Paulista, São Paulo, Brazil \\ ${ }^{\mathrm{b}}$ Department of Integrated Clinic, Araçatuba Dental School, UNESP-Univ Estadual Paulista, São Paulo, Brazil
}

\section{A R T I C L E I N F O}

\section{Article history:}

Received 9 June 2015

Received in revised form 8 March 2016

Accepted 18 March 2016

\section{Keywords:}

Electromyography

Jaw muscle

Mastication side

\begin{abstract}
A B S T R A C T
Objective: To compare electrical activity in the anterior temporal and masseter muscles on the habitual (HMS) and non-habitual mastication side (NHMS), during mastication and in the mandibular postural position. In addition, the increase in electrical activity during mastication was assessed for the HMS and NHMS, analysing both working (WSM) and non-working side during mastication (NWSM).

Methods: A total of 28 healthy women (18-32 years) participated in the study. They were submitted to Kazazoglu's test to identify the HMS. Bioresearch 'Bio EMG' software and bipolar surface electrodes were used in the exams. The exams were conducted in the postural position and during the unilateral mastication of raisins, on both the HMS and NHMS. The working and non-working side on HMS and NHMS were assessed separately. The obtained data were then statistically analysed with SPSS 20.0, using the Paired Samples Test at a significance level of $95 \%$.

Results: The differences in the average EMG values between HMS and NHMS were not statistically significant in the postural position (Temporal $\mathrm{p}=0.2$; Masseter $\mathrm{p}=0.4$ ) or during mastication (Temporal WSM $\mathrm{p}=0.8$; Temporal NWSM $\mathrm{p}=0.8$; Masseter WSM $\mathrm{p}=0.6$; Masseter NWSM $\mathrm{p}=0.2$ ). Differences in the increase in electrical activity between the masseter and temporal muscles occurred on the working side, on the HMS and NHMS ( $p=0.0)$, but not on the non-working side: HMS $(p=0.9)$ and NHMS $(p=0.3)$. The increase in electrical activity was about $35 \%$ higher in the masseter than in the temporal muscle. Conclusions: Mastication side preference does not significantly impact electrical activity of the anterior temporal and masseter muscles during mastication or in postural position.
\end{abstract}

(c) 2016 Elsevier Ltd. All rights reserved.

\section{Introduction}

Understanding the role of muscles in mastication has been the aim of many researchers (Delport, de Laat, Nijs, \& Hoogmartens, 1983; Diernberger, Bernhardt, Schwahn, \& Kordass, 2008; Gonçalves, Campos, Gonçalves, Moraes, \& Rodrigues Garcia, 2013; Nissan, Gross, Shifman, Tzadok, \& Assif, 2004; Shimizu et al., 2013; Varela et al., 2003). Mastication is a vital function that stimulates the jaw muscles, and maintains both bone (Shimizu, Ishida, Hosomichi, Kaneko, Hatano, \& Ono, 2013) and muscle quality (Gonçalves et al., 2013). Mastication can be exclusively unilateral

Abreviations: HMS, habitual mastication side; NHMS, non-habitual mastication side; WSM, working side during mastication; NWSM, non-working side during mastication; RDC, research diagnostic criteria; EMG, electromyography.

* Corresponding author. Permanent address: José Bonifácio Road, 1193, Araçatuba, SP CEP: 16015-050, Brazil.

E-mail addresses: karina@foa.unesp.br, luisfernandoc@ymail.com (K.H.L. Turcio). or alternating bilateral, considering that most people have a habitual mastication side, even those that present a bilateral alternating mastication pattern (Delport et al., 1983; Diernberger et al., 2008; Kazazoglu, Heath, \& Müller, 1994; Nissan et al., 2004; Varela et al., 2003). Preference for one side has been associated with better masticatory performance (Rovira-Lastra, FloresOrozco, Salsench, Peraire, \& Martinez-Gomis, 2014), although reports exist that unilateral mastication may be an aggravating factor for masseter hypertrophy (Skoura, Mourouzis, Saranteas, Chatzigianni, \& Tesseromatis, 2001). Masticatory laterality has also been related to biting force and occlusal contacts (Julien, Buschang, Throckmorton, \& Dechow, 1996; Lujan-Climent et al., 2008).

Many methods have been applied to identify the habitual mastication side, such as: the visual method, which relies on the observation of muscle contractions during mastication, in combination with electromyography (EMG) (Christensen \& Radue, 1985; Mohamed, Christensen, \& Harrison, 1983), electronic observation (Gomes, Custodio, Faot, Cury, \& Garcia, 2011) and visual inspection (Kazazoglu et al., 1994; Mc Donnell, Hector, \& Hannigan, 2004; 
Nissan et al., 2004; Varela et al., 2003). Varela et al. (2003) mentioned that this variety of methods may produce discrepancies in the obtained results.

EMG is one of the methods employed for the study of muscular function, and technological advancement in this field has turned EMG equipment into a useful tool applied by several authors on healthy volunteers (Sforza, Montagna, Rosati, \& Menezes, 2010) and on patients with temporomandibular disorders (TMD) (Tartaglia, Lodetti, Paiva, De Felicio, \& Sforza, 2011).

It is, however, important to emphasize that diagnoses should be based on a clinical assessment, supplemented with the findings of imaging studies (Okeson, 2012; Petersson, 2010).

The muscles most studied with EMG are the masseter and anterior temporal, because these can be assessed using surface electrodes (Svensson \& Graven-Nielsen, 2001), separately on the right and left side of the jaw (Nissan et al., 2004; Pita, Ribeiro, Garcia, Pedrazzi, \& Zuim, 2011).

Jaw muscle activity was related to bite force (Uchida et al., 2008) and mastication performance (Farias Gomes et al., 2010). In asymptomatic individuals the masseter and anterior temporal demonstrated an asymmetry between both sides during all functions, especially in the masseter during activities that involve little electrical activity, such as the postural position and centric occlusion (Ferrario, Sforza, Miani, D’Addona, \& Barbini, 1993). In female patients, the electrical activity of the temporal muscle tended to be higher at every contraction level than the masseter activity, whereas in male patients masseter activity was found to be more elevated during clenching than temporal activity (Ferrario et al., 1993).

Although at present few studies take mastication side preference into account (Rahal \& Goffi-Gomez, 2009), it may well be an important factor, because the recruitment patterns of some mastication muscles can vary for the production of the same jaw movement, and isotonic exercise may reduce this variability (Wirianski et al., 2014). It is possible that mastication plays a role in these patterns. In a study with healthy subjects, some authors affirm that the mastication muscles are highly adaptable and present decreases in electrical activity after long-term coordination exercises (Hellmann et al., 2011). According to Hellmann et al. (2011), there appears to exist an optimising recruitment strategy that may subsequently have reduced the initially redundant activation patterns by switching off redundant motor units. This affirmation is in accordance with the 'task group' hypothesis formulated by Loeb (1985). Our hypothesis was that the jaw muscles on the HMS demonstrate lower levels of electrical activity during mastication and in postural position than muscles on the NHMS.

The objective of this study was to assess whether mastication side preference influences electrical activity in the anterior temporal and masseter muscles in the postural position and during mastication.

\section{Materials and method}

\subsection{Selection of individuals}

All participants gave informed consent and the experiments were carried out in accordance with the principles of the Helsinki Declaration. Following approval by the Ethics Committee, 322 participants of this cross-sectional study were recruited among students of the Dentistry School of Araçatuba. The selection of participants was performed through anamnesis and a physical exam performed by an experienced professional.

The study was conducted with a sample of 28 female subjects (mean age 21.6 years, SD 3.7 years) from a group of 133 volunteers. Participants with the following characteristics were excluded: natural dentition of less than 24 teeth; TMD symptoms in accordance with Research Diagnostic Criteria (RDC) (Dworkin \& LeResche, 1992), currently undergoing medical treatment; neurological and metabolic systemic diseases; migraine; chronic pain; psychiatric disorders; and absence of a habitual mastication side.

\subsection{Verification of habitual (HMS) and non-habitual (NHMS) mastication side}

In order to verify the habitual mastication side, volunteers were submitted to a visual assessment using the method developed by Kazazoglu et al. (1994). Each individual chewed on a $30 \times 13 \times 4$ $\mathrm{mm}, 8.9 \mathrm{~g}$ chewing gum tablet (Trident Menthol, Cadbury Adams Ltd.). This test was performed without informing the participants beforehand, thus ensuring that knowledge of the experiment would not interfere with the choice for a particular mastication side. All volunteers were instructed to chew normally and were observed by an examiner for two consecutive minutes. During this period, they were interrupted 4 times to check on which side the gum was. This test was conducted twice in each individual so that an average could be obtained, allowing for the habitual mastication side to be classified as unilaterally left or right.

\subsection{Electromyographic exam}

The anterior temporal and masseter muscles were examined on both sides during the unilateral mastication of raisins and in the postural position. Prior to the exam, the participants were instructed to wash the part of their faces that corresponds with both muscles using water and soap. Then, the skin was rubbed with alcohol swabs (70\%) in order to reduce skin oiliness and impedance, thus improving signal conductivity.

Next, bipolar surface electrodes (Kendall Medtrace 100-ECG Conductive Adhesive Electrodes, Tyco Healthcare Group LP, Mansfield, Canada) were placed at intervals of $18 \mathrm{~mm}$ along the full extent of the masseter and anterior temporal muscles on both sides (Fig. 1)

The electrodes were wired to an amplifier, which transmitted the obtained muscle activity data to a computer equipped with the programme Bio EMG (Biopack-System Bio-Research, Inc., Milwaukee, Wisconsin, USA), band-pass filtered with a low frequency

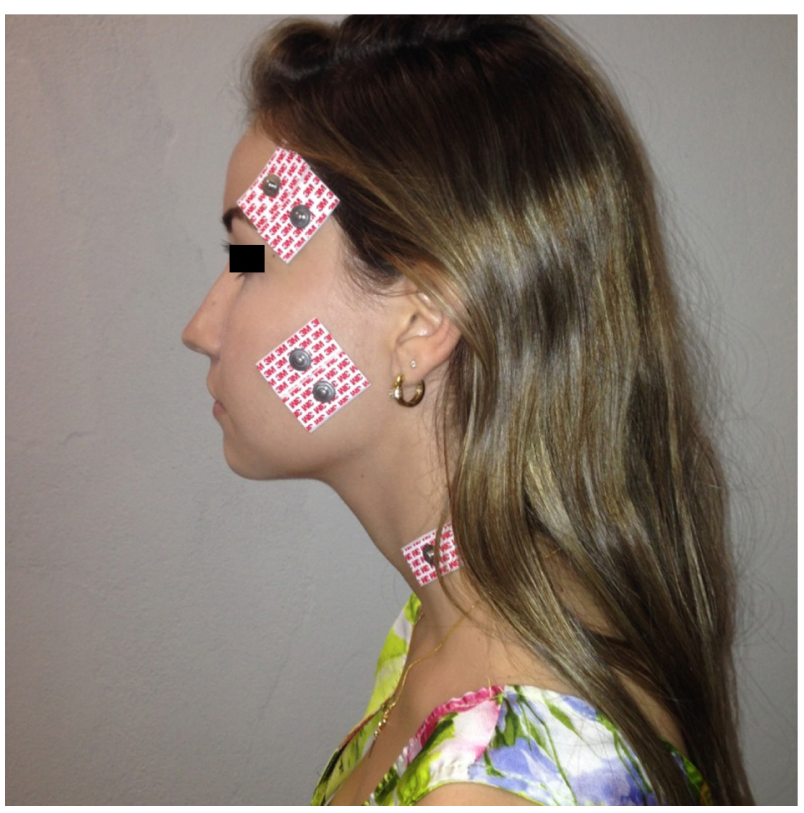

Fig. 1. Anterior temporal, masseter and reference electrodes position. 
cutoff at $30 \mathrm{~Hz}$, a high frequency cutoff at $500 \mathrm{~Hz}$, and a $1000 \mathrm{~Hz}$ sampling rate.

Data were registered for $10 \mathrm{~s}$ in both the postural position and during mastication of raisins on any side (random choice of the mastication side).

\subsection{Data analysis}

The analysis of electrical activity was performed at 2, 4, 6 and $8 \mathrm{~s}$ in the postural position. During mastication, the electrical activity from the second, fourth, sixth and eighth bite was analysed. The average activity was then calculated over the periods cited above. The electrical activity during mastication was monitored on the working (WSM, where the food was located) and non-working side (NWSM). This exam was performed three times in each patient, with one in the same phase of the menstrual cycle (follicular), which was verified using test kits that determine the day of the ovulation by measuring the luteinising hormone peak in urine at the end of the follicular phase ClearPlan Easy, Unipath Research, Princeton, NJ, USA).

The data were grouped into categories and, subsequently, the group averages and statistically significant differences were calculated. The following categories were established:

1. Electrical activity of the anterior temporal and masseter on HMS and NHMS in the postural position;

2. Electrical activity of the anterior temporal and masseter on HMS and NHMS during the mastication of raisins. The average muscle activity was calculated for the muscles on the working (WSM) and non-working (NWSM) sides of the jaw, which resulted in 8 average values: two for the temporal on the WSM (HMS and NHMS); two for the temporal on the NWSM (HMS and NHMS); two for the masseter on the WSM (HMS and NHMS); and two for the masseter on the NWSM (HMS and NHMS).

3. The difference in electrical activity between mastication and the postural position on the HMS and NHMS of WSM muscles, showing the increase in electrical activity when mastication commenced, for both the masseter and anterior temporal. This analysis resulted in 4 average values: two for the temporal on the WSM (HMS and NHMS); and two for the masseter on the WSM (HMS and NHMS).

4. The difference in electrical activity between mastication and the postural position on the HMS and NHMS of NWSM muscles, showing the increase in electrical activity when mastication commenced, for both the masseter and anterior temporal. This analysis resulted in 4 average values: two for the anterior temporal on the NWSM (HMS and NHMS); and two for the masseter on the NWSM (HMS and NHMS).

\subsection{Statistical analysis}

The data were statistically analysed using IBM SPSS 20.0. The Paired Samples $T$-test $(\mathrm{p} \leq 0.05)$ was conducted to evaluate the

\section{Table 1}

Comparison of EMG activity $(\mu \mathrm{V})$ and standard deviation (SD) $(n=28)$, during postural position of the mandible, of the anterior temporal and masseter muscles.

\begin{tabular}{|c|c|c|c|c|c|}
\hline \multirow{2}{*}{$\begin{array}{l}\text { Postural Position } \\
\text { Muscle }\end{array}$} & \multicolumn{2}{|c|}{$\mathrm{HS}(\mu \mathrm{V})$} & \multicolumn{2}{|l|}{ NHS $(\mu \mathrm{V})$} & \multirow[b]{2}{*}{ P Value } \\
\hline & Mean & SD & Mean & SD & \\
\hline Anterior temporal & 1.6 & 0.3 & 1.7 & 0.4 & 0.2 \\
\hline Masseter & 1.5 & 0.3 & 1.4 & 0.3 & 0.4 \\
\hline P Value & 0.1 & - & $\leq 0.0001^{*}$ & - & - \\
\hline
\end{tabular}

HS = habitual side of mastication. NHS = non habitual side of mastication. denotes statistically significant result.
EMG activity of the masseter and anterior temporal muscles on different habitual mastication sides and muscle activity (postural position and mastication).

\section{Results}

Table 1 shows the electrical activity in $\mu \mathrm{V}$ of the anterior temporal and masseter muscles in the postural position. It can be seen that there was no significant difference between HMS and NHMS. However, electrical activity was lower in the masseter than in the anterior temporal, with significance only on the NHMS $(\mathrm{P}<0.0001)$.

Tables 2-4, and Graph 1 demonstrate the electrical activity during mastication. Interestingly, it can be noted that the increase in electrical activity on the WSM was considerably higher in the masseter than in the temporal $(\leq 0.0001)$.

\section{Discussion}

The electrical activity of the masseter and anterior temporal muscles was assessed for the HMS and NHMS, and the activity of these muscles during unilateral mastication was measured electromyographically. Although both muscles contribute to occlusal force, the extent depends on the force generated by the muscle in a certain mandibular position. The pattern of muscle recruitment reflects the optimisation of the function of a particular muscle (Throckmorton \& Dean, 1994). Preference for one side during mastication may be an important factor in the physiology of jaw muscles, considering that the maintenance of bone density is related to the hardness of ingested foods (Shimizu et al., 2013). This suggests that unilateral mastication does not constitute an ideal function for the periodontium, since it generates different stimuli on the WSM and NWSM. Furthermore, it is important that the masticatory system is balanced, with masticatory forces acting as a stimulus for both the periodontium (Shimizu et al., 2013) and for muscles (Gonçalves et al., 2013).

Measuring mastication side preference was a challenge for the researchers, because several factors can influence, or even change the choice for one side (Martinez-Gomis et al., 2009). Most studies use chewing gum to measure this variable (Kazazoglu et al., 1994; Mc Donnell et al., 2004; Nissan et al., 2004; Varela et al., 2003). Some authors have, however, pointed out that the texture of food can affect mastication (Martinez-Gomis et al., 2009), which further complicates measuring the real mastication side preference of a person. This study opted for the test applied by Kazazoglu et al. (1994), which uses chewing gum. It allows for the easy visual observance of mastication patterns and considers full mastication cycles. In addition, the choice for chewing gum to verify

Table 2

Comparison of EMG activity $(\mu \mathrm{V})$ and standard deviation (SD) $(n=28)$, during mastication of raisins, of the anterior temporal and masseter muscles.

\begin{tabular}{llll}
\hline Mastication & & & \\
\hline Muscle/Side & mean $(\mu \mathrm{V})$ & SD & P value \\
\hline Anterior temporal HS/WS & 46.7 & 21.1 & \\
Anterior temporal NHS/WS & 46.2 & 21.8 & 0.8 \\
Anterior temporal HS/NWS & 39.1 & 16.8 & \\
Anterior temporal NHS/NWS & 39.6 & 18.1 & 0.8 \\
Masseter HS/WS & 71.4 & 33.5 & \\
Masseter NHS/WS & 73.7 & 31.0 & 0.6 \\
Masseter HS/NWS & 38.5 & 18.8 & \\
Masseter NHS/NWS & 35.3 & 16.9 & 0.2
\end{tabular}

" denotes statistically significant result.

$\mathrm{HS}=$ habitual side of mastication.

$\mathrm{NHS}=$ non habitual side of mastication

WS $=$ working side

NWS = non-working side 
Table 3

Comparison of the increase (mastication minus rest) in EMG activity $(\mu \mathrm{V})$ during mastication of raisins $(n=28)$, of the anterior temporal and masseter muscles.

\begin{tabular}{|c|c|c|c|c|c|c|}
\hline \multirow[b]{4}{*}{ Muscle } & \multicolumn{6}{|c|}{ Increase in EMG activity } \\
\hline & \multicolumn{2}{|l|}{ WS } & \multirow[b]{3}{*}{ P Value } & \multirow{2}{*}{\multicolumn{2}{|c|}{$\frac{\text { NWS }}{\text { Mean }(\mu V)}$}} & \multirow[b]{3}{*}{ P Value } \\
\hline & \multicolumn{2}{|c|}{ Mean $(\mu \mathrm{V})$} & & & & \\
\hline & HS & NHS & & HS & NHS & \\
\hline Anterior temporal & 45.0 & 44.5 & 0.8 & 37.4 & 38.0 & 0.8 \\
\hline Masseter & 69.0 & 72.2 & 0.5 & 37.0 & 33.8 & 0.1 \\
\hline P Value & $\leq 0.0001^{*}$ & $\leq 0.0001^{*}$ & - & 0.91 & 0.3 & - \\
\hline
\end{tabular}

$\mathrm{HS}=$ habitual side of mastication.

NHS $=$ non habitual side of mastication.

WS $=$ working side

NWS = non-working side.

denotes statistically significant result.

mastication side preference is based on the fact that gum doesn't disintegrate and is therefore more convenient (Paphangkorakit, Thothongkam, \& Supanont, 2006).

Electromyographic studies, as a supporting diagnostic element in the patient exam, seek to create a reference to what could be considered a disharmony or dysfunction of the masticatory system. They have also been used to objectively assess the effectivity of several treatment modalities, but the clinical use of EMG to diagnose temporomandibular disorders is not recommended (Suvinen \& Kemppainen, 2007). In this study, EMG was employed to evaluate the electrical activity of the mastication muscles in healthy individuals, which, according to Suvinen and Kemppainen (2007), is its primary application. The obtained results confirm that in the postural position, electrical activity in the muscles of asymptomatic individuals is minimal and concentrated in the anterior temporal, which corresponds with the results found in other studies (Ferrario et al., 1993; Hairston \& Blanton, 1983). According to Ferrario et al. (1993), this is particularly true for female patients, considering that only $30 \%$ of the patients in their study demonstrated higher activity levels in the masseter muscles whilst in the postural position. An important fact to point out, according to Miles (2007), is the position of an individual's head. When the head is in an orthostatic position, there is a very lowlevel alternating activity in the jaw opening and closing muscles, which suggests that a passive viscoelastic force offered by perioral tissues sustains the postural position.

The use of EMG for data normalisation is common in the current literature (Cecílio et al., 2010). However, it is important to note that data normalisation is still a much debated issue. Despite De Luca's (1997) defence of the normalisation of EMG data, he acknowledges that it can suppress important differences. For this reason, we opted for analysis of the difference in activity between the postural

\section{Table 4}

Comparison of the increase (mastication minus rest) in EMG activity $(\mu \mathrm{V})$ between working side of mastication (WS) and non-working side of mastication (NWS) during mastication of raisins $(n=28)$.

\begin{tabular}{llllll}
\hline & \multicolumn{3}{l}{ Increase in EMG activity } & & \\
\cline { 2 - 3 } & \multicolumn{2}{l}{ Habitual side of mastication } & & Non-habitual side of mastication \\
\cline { 2 - 3 } \cline { 5 - 6 } & Mean $(\mu \mathrm{V})$ & & & Mean $(\mu \mathrm{V})$ & \\
& Anterior temporal & Masseter & & Temporal $(\mu \mathrm{V})$ & Masseter $(\mu \mathrm{V})$ \\
\hline WS & 45.0 & 69.0 & & 44.5 & 72.2 \\
NWS & 37.4 & 37.0 & & 38.00 & 33.8 \\
P Value & $0.003^{*}$ & $\leq 0.000^{*}$ & $0.014^{*}$ & $\leq 0.000^{*}$ \\
\hline
\end{tabular}

denotes statistically significant result. position and mastication without normalising the data. The use of EMG is questionable when group averages are used for comparison, which is why this study statistically compared the differences between the postural position and mastication in individuals rather than between groups.

In the postural position mastication side preference did not influence muscle activity, although it was noted that the electrical activity of the temporal muscle was higher than that of the masseter on the NHMS (Table 1 ). It is possible that mastication side preference elevates the tonus of the temporal muscle on the opposite side, considering that this is the positioner. The fact that the participants of this study were asymptomatic individuals implies that the assessed muscles generally have a good structural tolerance, which may explain the low increase in muscle tonus. It is therefore important that further studies with symptomatic patients are conducted in order to verify whether mastication side preference is caused by an elevation in the tonus of the NHMS positioner muscle. Despite the difference between jaw sides, low degrees of electrical activity were observed in the postural position on both sides and in both muscles, which corresponds with the finds of Ferrario et al. (1993) regarding asymptomatic individuals.

Table 2 shows that the muscle activity during mastication was not influenced by mastication side preference. However, as indicated in Table 3, the increase in electrical activity (mastication minus postural position) was significantly higher in the masseter than in the temporal muscle on the working side, which confirms that EMG studies aimed at verifying mastication side preference should focus on the masseter (Christensen \& Radue, 1985; Mohamed et al., 1983). Mastication side preference was not the most important determiner of electrical muscle activity, since a comparison between HMS and NHMS did not reveal significant increases in either of the analysed muscles (Table 3). The working side on the other hand, did. If food texture can affect mastication patterns and the choice for a particular mastication side (MartinezGomis et al., 2009), it is possible that the participants of this study chew other types of food with a different side. This means that both sides of the jaw would receive stimuli, thus minimising the differences between HMS and NHMS.

On the other hand, the significantly higher activity on the working side indicates that during mastication, the masseter works at a higher intensity than the temporal muscle, even though activity of the latter also increases. This can cause a higher stimulus on one of the sides, especially in combination with a parafunctional habit like using chewing gum. Furthermore, unilateral mastication may stimulate one side of the masseter, and in cases of excessive use of chewing gum, this can lead to fatigue or even hypertrophy of the masseter on that side. It is therefore important that patients with a habitual mastication side are made aware of the potential consequences of unilateral mastication, and that orientations aimed at achieving an adequate occlusion are provided.

\section{Conclusion}

Mastication side preference does not significantly impact electrical activity of the anterior temporal and masseter muscles during mastication or in the postural position.

\section{Conflict of interest}

None.

\section{Ethical approval}

The procedures adopted for this search meet the criteria of the Ethics in Human Research Participation in this research does not 
infringe the legal and ethical standards as all patients will be only undergoing non-invasive diagnostic tests.

\section{References}

Cecílio, F. A., Regalo, S. C., Palinkas, M., Issa, J. P., Siéssere, S., Hallak, J. E., et al. (2010). Ageing and surface EMG activity patterns of masticatory muscles. Journal of Oral Rehabilitation, 37, 248-255.

Christensen, L. V., \& Radue, J. T. (1985). Lateral preference in mastication: an electromyographic study. Journal of Oral Rehabilitation, 12, 429-434.

De Luca, C. J. (1997). The use of surface electromyography in biomechanics. Journal of Applied Biomechanics, 13, 135-163.

Delport, H. P., de Laat, A., Nijs, J., \& Hoogmartens, M. J. (1983). Preference pattern of mastication during the first chewing cycle. Electromyography and Clinical Neurophysiology, 23, 491-500.

Diernberger, S., Bernhardt, O., Schwahn, C., \& Kordass, B. (2008). Self-reported chewing side preference and its associations with occlusal: temporomandibular and prosthodontic factors: results from the population-based Study of Health in Pomerania (SHIP-0). Journal of Oral Rehabilitation, 35, 613-620.

Dworkin, S. F., \& LeResche, L. (1992). Research diagnostic criteria for temporomandibular disorders: review, criteria, examinations and specifications critique. Journal of Craniomandibular Disorders, 6, 301-355.

Farias Gomes, S. G., Custodio, W., Moura Jufer, J. S., Del Bel Cury, A. A., \& Rodrigues Garcia, R. C. (2010). Correlation of mastication and masticatory movements and effect of chewing side preference. Brazilian Dental Journal, 21, 351-355.

Ferrario, V. F., Sforza, C., Miani, A. Jr., D’Addona, A., \& Barbini, E. (1993) Electromyographic activity of human masticatory muscles in normal young people: statistical evaluation of reference values for clinical applications. Journal of Oral Rehabilitation, 20, 271-280.

Gomes, S. G., Custodio, W., Faot, F., Cury, A. A., \& Garcia, R. C. (2011). Chewing side, bite force symmetry: and occlusal contact area of subjects with different facial vertical patterns. Brazilian Oral Research, 25, 446-452.

Gonçalves, T. M., Campos, C. H., Gonçalves, G. M., Moraes, M., \& Rodrigues Garcia, R. C. (2013). Mastication improvement after partial implant-supported prosthesis use. Journal of Dental Research, 92, 189S-194S.

Hairston, L. E., \& Blanton, P. L. (1983). An electromyographic study of mandibular position in response to changes in body position. Journal of Prosthetic Dentistry, 49, 271-275.

Hellmann, D., Giannakopoulos, N. N., Blaser, R., Eberhard, L., Rues, S., \& Schindler, H. J. (2011). Long-term training effects on masticatory muscles. Journal of Oral Rehabilitation, 38, 912-920.

Julien, K. C., Buschang, P. H., Throckmorton, G. S., \& Dechow, P. C. (1996). Normal masticatory performance in young adults and children. Archives of Oral Biology 41, 69-75.

Kazazoglu, E., Heath, M. R., \& Müller, F. (1994). A simple test for determination of the preferred chewing side. Journal of Oral Rehabilitation, 21, 723.

Loeb, G. E. (1985). Motoneurone task groups: coping with kinematic heterogeneity. Journal of Experimental Biology, 115, 137-146.

Lujan-Climent, M., Martinez-Gomis, J., Palau, S., Ayuso-Montero, R., Salsench, J., et al. (2008). Influence of static and dynamic occlusal characteristics and muscle force on masticatory performance in dentate adults. European Journal of Oral Sciences, 116, 229-236.

Martinez-Gomis, J., Lujan-Climent, M., Palau, S., Bizar, J., Salsench, J., \& Peraire, M. (2009). Relationship between chewing side preference and handedness and lateral asymmetry of peripheral factors. Archives of Oral Biology, 54, 101-107.

Mc Donnell, S. T., Hector, M. P., \& Hannigan, A. (2004). Chewing side preferences in children. Journal of Oral Rehabilitation, 31, 855-860.
Miles, T. S. (2007). Postural control of the human mandible. Archives of Oral Biology, 52, 347-352.

Mohamed, S. E., Christensen, L. V., \& Harrison, J. D. (1983). Tooth contact patterns and contractile activity of the elevator jaw muscles during mastication of two different types of food. Journal of Oral Rehabilitation, 10, 87-95.

Nissan, J., Gross, M. D., Shifman, A., Tzadok, L., \& Assif, D. (2004). Chewing side preference as a type of hemispheric laterality. Journal of Oral Rehabilitation, 31, 412-416.

Okeson, J. P. (2012). Management of temporomandibular disorders and occlusion, 7th ed. St. Louis: Elsevier.

Paphangkorakit, J., Thothongkam, N., \& Supanont, N. (2006). Chewing-side determination of three food textures. Journal of Oral Rehabilitation, 33, 2-7.

Petersson, A. (2010). What you can and cannot see in TM: J imaging - an overview related to the RDC/TMD diagnostic system. Journal of Oral Rehabilitation, 37, 771-778.

Pita, M. S., Ribeiro, A. B., Garcia, A. R., Pedrazzi, V., \& Zuim, P. R. (2011). Effect of occlusal splint thickness on electrical masticatory muscle activity during rest and clenching. Brazilian Oral Research, 25, 506-511.

Rahal, A., \& Goffi-Gomez, M. V. (2009). Clinical and electromyographic study of lateral preference in mastication in patients with longstanding peripheral facial paralysis. International Journal of Orofacial Myology, 35, 19-32.

Rovira-Lastra, B., Flores-Orozco, E. I., Salsench, J., Peraire, M., \& Martinez-Gomis, J. (2014). Is the side with the best masticatory performance selected for chewing? Archives of Oral Biology, 59, 1316-1320.

Sforza, C., Montagna, S., Rosati, R., \& Menezes, M. (2010). Immediate effect of an elastomeric oral appliance on the neuromuscular coordination of masticatory muscles: a pilot study in healthy subjects. Journal of Oral Rehabilitation, 37, $840-$ 847.

Shimizu, Y., Ishida, T., Hosomichi, J., Kaneko, S., Hatano, K., \& Ono, T. (2013). Soft diet causes greater alveolar osteopenia in the mandible than in the maxilla. Archives of Oral Biology, 58, 907-911.

Skoura, C., Mourouzis, C., Saranteas, T., Chatzigianni, E. \& Tesseromatis, C. (2001) Masseteric hypertrophy associated with administration of anabolic steroids and unilateral mastication: a case report. Oral Surgery, Oral Medicine, Oral Pathology, Oral Radiology, and Endodontics, 92, 515-518.

Suvinen, T. I., \& Kemppainen, P. (2007). Review of clinical EMG studies related to muscle and occlusal factors in healthy and TMD subjects. Journal of Oral Rehabilitation, 34, 631-644.

Svensson, P., \& Graven-Nielsen, T. (2001) Craniofacial muscle pain: review of mechanisms and clinical manifestations. Journal of Orofacial Pain, 15, 117-145.

Tartaglia, G. M., Lodetti, G., Paiva, G., De Felicio, C. M., \& Sforza, C. (2011). Surface electromyographic assessment of patients with long lasting temporomandibular joint disorder pain. Journal of Electromyography and Kinesiology, 21, 659-664.

Throckmorton, G. S., \& Dean, J. S. (1994). The relationship between jaw-muscle mechanical advantage and activity levels during isometric bites in humans. Archives of Oral Biology, 39, 429-437.

Uchida, S., Iwasaki, L. R., Marx, D. B., Yotsui, Y., Inoue, H., \& Nickel, J. C. (2008). Variations in activities of human jaw muscles depend on tooth-tipping moments. Archives of Oral Biology, 53, 199-205.

Varela, J. M., Castro, N. B., Biedma, B. M., Silva Domínguez, J. L., Quintanilla, J. S., Muñoz, F. M., et al. (2003). A comparison of the methods used to determine chewing preference. Journal of Oral Rehabilitation, 30, 990-994.

Wirianski, A., Deall, S., Whittle, T., Wong, M., Murray, G. M., \& Peck, C. C. (2014). Isotonic resistance jaw exercise alters jaw muscle coordination during jaw movements. Journal of Oral Rehabilitation, 41,353-366. 